\title{
Fas-positive lymphocytes are associated with systemic inflammation in obstructive sleep apnea syndrome
}

\author{
Joanna Domagała-Kulawik ${ }^{1} \cdot$ Iwona Kwiecień $^{2} \cdot$ Piotr Bielicki $^{1} \cdot$ Tomasz Skirecki $^{3}$ (D)
}

Received: 11 April 2018 / Revised: 20 August 2018 / Accepted: 22 August 2018 / Published online: 31 August 2018

(C) The Author(s) 2018

\begin{abstract}
Purpose Obstructive sleep apnea syndrome (OSAS) is associated with alterations in immune system which may lead to serious complications. The aim of this study was to explore lymphocyte populations in OSAS with special attention to the Fas-positive cells.

Methods Fifty-one patients with confirmed OSA and 20 healthy subjects were investigated. The OSA severity indices, data concerning comorbidities, and markers of inflammation and metabolic disorders were collected. Flow cytometry was used to analyze the lymphocyte profile and expression of Fas receptors (CD95). Concentration of adiponectin, IL-1 $\beta$, TNF- $\alpha$, and sFas were measured.

Results Proportions of Fas-positive cells in the pool of CD4+ and Fas-positive in the pool of CD8+ cells in the blood of patients were significantly increased when compared with healthy subjects $(74.5 \%$ vs. $65.6 \%$ and $78.8 \%$ vs. $70.9 \%$, respectively, $p<0.05$ ). No correlation with OSA severity was found. However, the proportion and number of Fas + cells were elevated in obese patients, in non-smokers, and in patients suffering from COPD and hypertension. There were several significant relations of Fas+ cells with inflammatory markers of systemic inflammation.

Conclusion Lymphocytes with the expression of Fas receptor are associated with systemic inflammation in OSAS.
\end{abstract}

Keywords OSAS $\cdot$ Lymphocytes $\cdot$ Fas receptor $\cdot$ Systemic inflammation

\section{Introduction}

Obstructive sleep apnea syndrome (OSAS) is a breathing disorder during sleep, which is known to be connected with obesity, metabolic syndrome, and the risk of cardiovascular complications and especially risk of arterial hypertension. OSAS and related complications are accompanied by systemic inflammation $[1,2]$. We previously reported significant changes

Tomasz Skirecki

tskirecki@gmail.com

1 Department of Internal Medicine, Pulmonary Diseases and Allergy, Medical University of Warsaw, ul. Banacha 1a, 02 097 Warsaw, Poland

2 Laboratory of Flow Cytometry, Department of Internal Medicine and Hematology, Military Medical Institute, ul. Szaserow 128, 04 141 Warsaw, Poland

3 Laboratory of Flow Cytometry, Department of Anesthesiology and Intensive Care, Centre of Postgraduate Medical Education, ul. Marymoncka 99/103, 01813 Warsaw, Poland in the proportion of blood lymphocytes in OSA patients. The proportion of B cells, $\mathrm{Th} / \mathrm{Tc}$ ratio, and adiponectin concentration were lower but, the proportion of Tc, NK, NKT-like, and HLA-DR positive T cells were elevated in OSAS patients when compared with healthy subjects and these changes correlated with metabolic complications [3]. In this study, we aimed to further evaluate blood lymphocyte characteristics by the analysis of the expression of Fas receptor on the main lymphocyte subtypes. Fas (CD95) is a death receptor and belongs to the tumor necrosis factor receptor (TNFR) superfamily. Recently, its role in the modulation of immune response was described and it was found that the role of Fas/ FasL pathway is wider than previously thought [4-6]. It was described, among others, that Fas/FasL signaling contributes to antigen-presenting cell activation, activation-induced cell death of $\mathrm{T}$ cells and thus to a maintenance of $\mathrm{T}$ cells homeostasis, Th17 differentiation, and precocious differentiation of memory T cells [4-6]. Therefore, the relationship of Faspositive cells with markers of systemic inflammation, metabolic complications, OSA severity, and inflammatory cytokine concentration was of interest to this study. 


\section{Material and methods}

Fifty-one patients with confirmed OSAS were enrolled into the study. The diagnosis of OSAS was established in accordance with the American Academy of Sleep Medicine (AASM) and Polish Respiratory Society recommendations $[7,8]$. A polysomnography test (PSG) was executed using the Alice 4 apparatus (RESPIRONICS, USA). The criteria of diagnosis were the apnea/hypopnea index (AHI) value over 5 and the Epworth Sleepiness Scale (ESS) over 10 points. The control group consisted of 20 healthy volunteers without any chronic disease. The study was approved by the Ethics Committee of the Medical University of Warsaw and all the participants gave informed consent. The venous blood samples were collected before breakfast, early in the morning. All the analyses were performed right after blood collection. We analyzed the proportions of the following lymphocyte subtypes: $\mathrm{T}$ cells, B cells, $\mathrm{T}$ helper (Th) and T cytotoxic cells (Tc), natural killer (NK), natural killer T cells (NKT-like), and T cells with HLA-DR expression by Simultest (BD, San Jose, California, US). Flow cytometry analysis was performed as previously described [3]. For the analysis of Fas receptor expression on $\mathrm{T}$ cells, the following cocktail of antibodies was used: CD4-FITC/CD8-PE/CD95-PE-Cy5. Briefly, anti-CD45FITC and anti-CD14-PE were used for the lymphocyte gate setting at FSC/SSC graph (Fig. 1). Negative isotype controls with IgG1-FITC/IgG2a-PE were applied. The analyses were performed using FACS Canto II flow cytometer (Becton-Dickinson, San Jose, California) and Diva software (BD). Ten thousand lymphocytes were collected. Geometric mean fluorescence (GMF) intensity of Fas staining on $\mathrm{T}$ cells was measured. The serum concentrations of adiponectin, soluble Fas, interleukin-1 $\beta$ (IL-1 $\beta$ ), and tumor necrosis factor (TNF- $\alpha$ ) were measured using commercially available ELISA kits: Human Total Adiponectin/Acrp30 Immunoassay kit, HS ELISA Human Fas/TNFRSF6, Human IL-1 beta/IL-1F2, Human TNFalpha Quantikine ELISA Kit (R\&D System, USA), according to the prescription by the producer. a

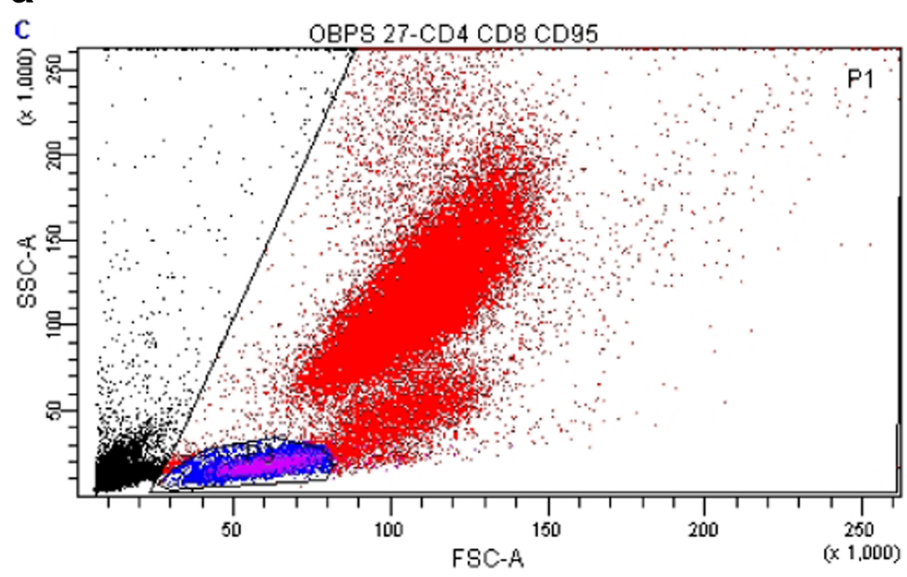

C

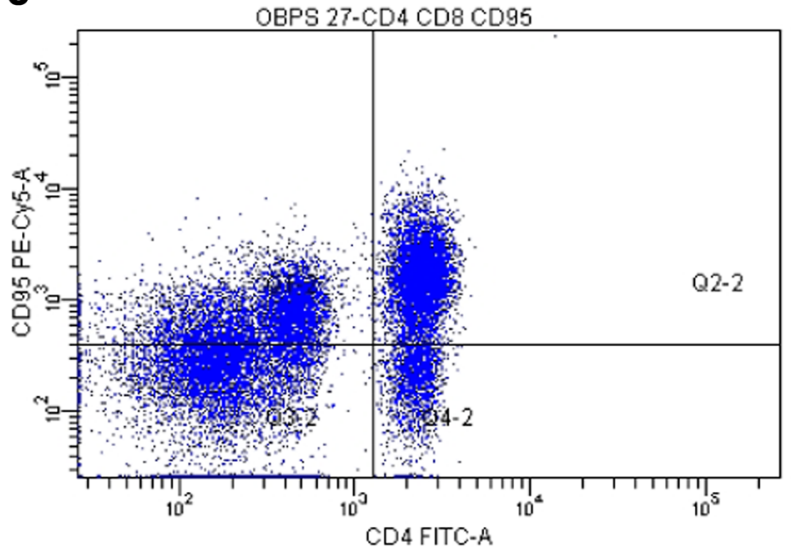

b

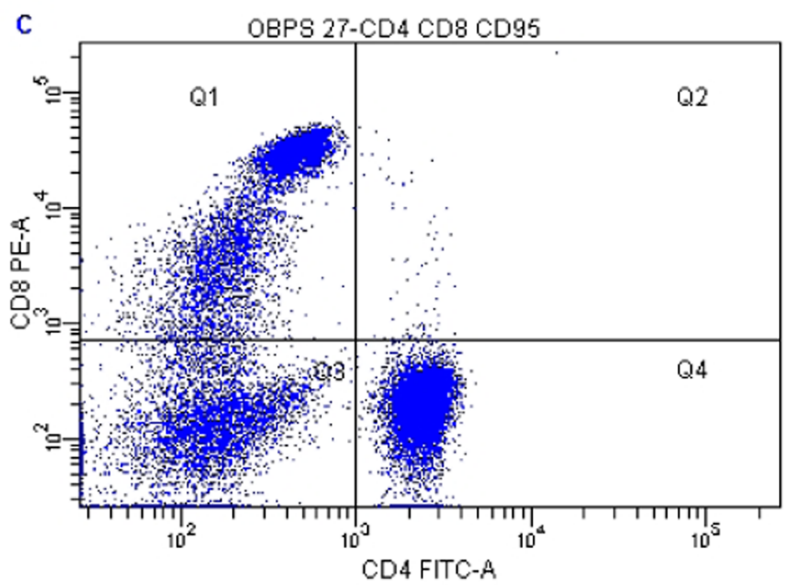

d

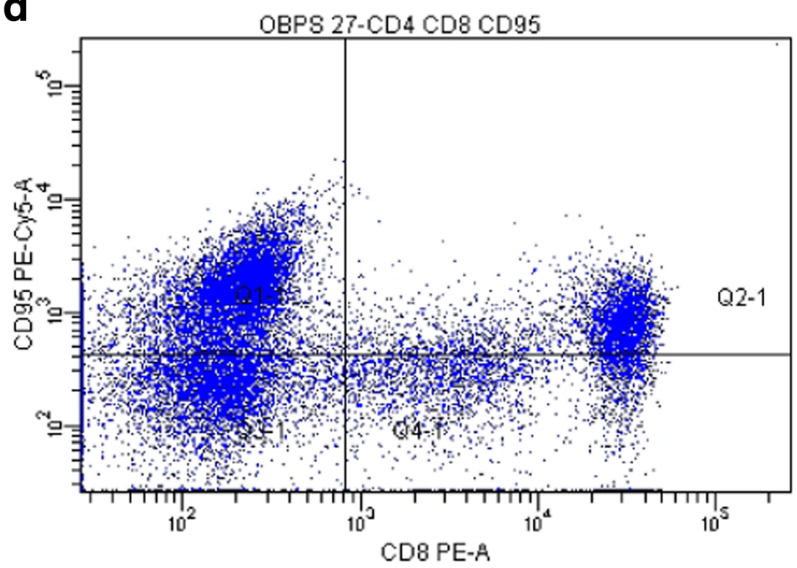

Fig. 1 Representative flow cytometry analysis of Fas expression in blood lymphocytes in OSA patient. a Morphological gate for lymphocytes is shown, b then CD4+ and CD8+ cells are gated. Analysis of Fas (CD95) expression on $\mathbf{c}$ CD4+ and $\mathbf{d ~ C D 8 + ~ T ~ c e l l s ~}$ 


\section{Statistical analysis}

For data comparison, the Mann-Whitney $U$ test was applied. A $p$ value of less than 0.05 was regarded as significant. The relationships between the data were examined by the Spearman's rank correlation coefficient. Correlations with both $r \geq 0.3$ and $p<0.05$ were considered relevant.

\section{Results}

Of 51 patients with OSAS (35 men, 69\%), mean age was 58 years (range 36-82); 33\% were smokers with mean 15 pack-years. The control group of 20 subjects ( 8 men, $40 \%$ ) had a mean age of 46 years (range 30-76) and normal BMI; $50 \%$ were smokers with mean 32 pack-years. For these characteristics, the control group did not differ significantly from the study group. The following OSAS indices characterized the patient group: mean BMI was $31.7 \mathrm{~kg} / \mathrm{m}^{2}$ and obesity was recognized in 52\%; mean AHI was $53 \pm 21$, ODI was $31 \pm 19$, EES was $12.2 \pm 5.3$, and mean lowest peripheral capillary oxygen saturation $\left(\mathrm{SpO}_{2}\right)$ was $76 \pm 9 \%$. Severe OSAS was categorized in $86 \%$ of patients. The mean values of white blood cell count, concentration of hemoglobin, plasma glucose, total cholesterol (TC), triglycerides (TG), high-density lipoprotein cholesterol (HDL-C), and $\mathrm{C}$ reactive protein (CRP) were within normal range. However, in $11 \%$ of the patients, the concentration of TG was higher than $200 \mathrm{mg} / \mathrm{dL}$ and in $49 \%$, cholesterol $>200 \mathrm{mg} / \mathrm{dL}$. In $52 \%$ of patients, features of metabolic syndrome were recognized. Distribution of patients in each group of OSAS complication score (defined according to [3]) was as follows: score 0 (4), score 1 (14), score 2 (19), score 3 (7), score 4 (4), and score 5 (1). Hypertension was recognized in $72 \%$ and COPD in $7 \%$ of patients.

The gating strategy for the Fas expression analysis is shown in Fig. 1. We present the proportion of Fas-positive cells as a percentage of all lymphocytes (Fas+CD4+ and Fas+CD8+ cells) as well as percentage of Fas-positive cells among all $\mathrm{CD} 4+$ cells (\%Fas in $\mathrm{CD} 4+)$ and among all $\mathrm{CD} 8+$ cells (\%Fas in CD8+). As for the total cell counts, there were mean $464 \pm 242$ Fas+CD4+ cells $/ \mu L$, and $494.4 \pm 272$ Fas + $\mathrm{CD} 8+$ cells $/ \mu \mathrm{L}$ of peripheral blood. We found significantly higher proportions of Fas-positive cells in the OSAS patients than in the control subjects (Table 1). In the OSAS patients, the expression of Fas (expressed as GMF) on CD4+ cells was $766.6 \pm 312$ and it significantly correlated with the Fas expression on CD8+ cells $(r=0.7, p<0.05)$ which was $693.4 \pm 271$. The age and sex had no influence on Fas+ cells proportion (apart from weak correlation of proportion of Fas+CD8+ cells with age).

The median concentration of sFas was 1911.4 (1759.42053.4) $\mathrm{pg} / \mathrm{mL}$ and did not differ when compared with that of the control group (2062.7 (1826.1-2090.1) pg/mL). No correlations of sFas concentration with clinical data, OSA severity, nor cell proportions were found. We did not find any correlations of IL-1 $(0.3(0.1-05) \mathrm{pg} / \mathrm{mL})$ nor TNF- $\alpha$ $(1.22(0.7-13.9) \mathrm{pg} / \mathrm{mL})$ concentration with patient data.

We analyzed the relationships between Fas-positive T cell percentage with (a) other immune cells and mediators, (b) OSA indices, (c) metabolic disorders, (d) comorbidities, and (e) smoking history. The results of this analysis are presented in Table 1 and Fig. 2.

\section{Discussion}

There is a growing body of evidence that the nature of OSAS and systemic complications of this pathology are connected with immune system alterations. However, precise data on the nature of inflammation are still scanty. In our previous study, we observed significant changes in the populations of circulating inflammatory cells, i.e., lymphocytes B, cytotoxic T (Tc), NK, and NKT-like cells, and in the concentration of adiponectin in OSAS. Our recent investigation revealed an involvement of death receptor Fas in the inflammatory process of severe OSA. Here, we presented Fas-positive cells as proportion of lymphocytes, as proportion of lymphocyte subpopulations, as absolute number, and as cell surface expression of this receptor. It allowed us to assess objectively the expression of the Fas receptors among T cells. Our study group consisted of patients with severe OSAS and our findings might reflect adaptive processes of the immune system. The negative correlation of oxygen saturation with Fas expression seems to confirm this hypothesis. Recently obtained data showing the pivotal role of the Fas/FasL signaling pathway in maintaining the homeostasis of immune system [6] supports the value of our study.

Our current findings on the Fas expression are especially marked in the CD8+ cell population. Dyugovskaya et al. showed that CD8+ cells form the most affected population in OSAS [9]. Tan et al. found a high proportion of CD8+ cells and a low proportion of $\mathrm{CD} 4+$ cells according to the $\mathrm{AHI}$ in children suffering from OSAS [10]. CD8+ cells constitute the $\mathrm{T}$ cell subpopulation which contributes to the formation of atherosclerotic lesions [11]. We previously reported an elevated proportion of lymphocytes with Fas expression in patients with lung cancer and in COPD $[12,13]$. In the current study, the proportion of Fas-positive cells was much higher in OSA/ COPD overlap syndrome which is in line with the hypothesized role of CD8+ cells in COPD pathogenesis. In our previous studies, tobacco smoking was investigated as a factor capable of affecting the immune system. In fact, the proportion of Fas-positive lymphocytes was highly correlated with the intensity of tobacco exposure $[12,13]$. Unexpectedly, we found an opposite result in the present study. However, as we 
Table 1 Proportion of T lymphocytes with expression of Fas in the blood of OSA patients and control group and the relationship with clinical data and inflammatory markers. Data expressed as median values and quartiles $\mathrm{p} 25-\mathrm{p} 75, p<0.05$, and $r \geq 0.3$ are considered significant

\begin{tabular}{|c|c|c|c|c|c|}
\hline & & \multicolumn{2}{|l|}{$\mathrm{Fas}^{+} \mathrm{CD} 4^{+}$} & \multicolumn{2}{|l|}{$\mathrm{Fas}^{+} \mathrm{CD}^{+}$} \\
\hline & & $\begin{array}{l}\mathrm{Fas}^{+} \mathrm{CD} 4^{+} \\
{[\% \text { of lymphocytes] }}\end{array}$ & $\begin{array}{l}\mathrm{Fas}^{+} \\
{\left[\% \text { of all CD } 4^{+} \text {cells }\right]}\end{array}$ & $\begin{array}{l}\mathrm{Fas}^{+} \mathrm{CD}^{+} \\
{[\% \text { of lymphocytes }]}\end{array}$ & $\begin{array}{l}\mathrm{Fas}^{+} \\
{\left[\% \text { of all } \mathrm{CD} 8^{+} \text {cells }\right]}\end{array}$ \\
\hline & Patients & 25.9 & 74.5 & 28.5 & 78.8 \\
\hline & & $20.4-33.5$ & $58.7-93.7$ & $22.0-40.1$ & $65.7-92.8$ \\
\hline & Control group & 28.1 & 65.6 & 19.0 & 70.9 \\
\hline & & $23.6-31.4$ & $60.2-72.6$ & $16.6-22.7$ & $58.8-76.0$ \\
\hline & $p$ & $>0.05$ & 0.05 & 0.002 & 0.004 \\
\hline \multicolumn{6}{|l|}{ Relation with: } \\
\hline \multirow{12}{*}{$\begin{array}{l}\text { 1. Other immune cells } \\
\text { and mediators of } \\
\text { inflammation }\end{array}$} & PMN & \multicolumn{2}{|c|}{$\mathrm{Fas}^{+} \mathrm{CD} 4^{+} / \mu \mathrm{L} r=-0.3, p<0.05$} & \multicolumn{2}{|c|}{$\mathrm{Fas}^{+} \mathrm{CD}^{+} / \mu \mathrm{L} r=-0.3, p<0.05$} \\
\hline & PLT & \multicolumn{2}{|c|}{$\mathrm{GMF} \mathrm{Fas}^{+} \mathrm{CD}^{+} r=-0.3, p<0.05$} & \multicolumn{2}{|c|}{$\begin{array}{l}\mathrm{Fas}^{+} \mathrm{CD}^{+} \% r=-0.3, p<0.05 \\
\mathrm{GMF} \mathrm{Fas}^{+} \mathrm{CD} 8^{+} r=-0.3, p<0.05\end{array}$} \\
\hline & CD19\% & & & \multicolumn{2}{|c|}{$\mathrm{Fas}^{+} \mathrm{CD} 8^{+} \% r=-0.3, p<0.05$} \\
\hline & CD19/ul & \multicolumn{2}{|c|}{$\mathrm{Fas}^{+} \mathrm{CD}^{+} \% r=-0.3, p<0.05$} & $\mathrm{Fas}^{+} \mathrm{CD} 8^{+} / \mu \mathrm{L} r=-0$ & $p<0.05$ \\
\hline & & \multicolumn{4}{|c|}{$\mathrm{GMF} \mathrm{Fas}^{+} \mathrm{CD}^{+} r=-0.4, p<0.05$} \\
\hline & $\mathrm{NK} \%$ & \multicolumn{4}{|c|}{$\mathrm{Fas}^{+} \mathrm{CD}^{+} \% r=0.3, p<0.05$} \\
\hline & $\mathrm{NK} / \mathrm{ul}$ & \multirow{2}{*}{\multicolumn{2}{|c|}{$\mathrm{Fas}^{+} \mathrm{CD}^{+} / \mu \mathrm{L} r=0.5, p<0.05$}} & \multicolumn{2}{|c|}{$\mathrm{Fas}^{+} \mathrm{CD}^{+} / \mu \mathrm{L} r=-0.3, p<0.05$} \\
\hline & NKT\% & & & $\mathrm{Fas}^{+} \mathrm{CD}^{+} \% r=0.5$, & $<0.05$ \\
\hline & CD3+/HLA-DR + \% & \multicolumn{2}{|c|}{$\mathrm{Fas}^{+} \mathrm{CD}^{+} \% r=0.3, p<0.05$} & \multicolumn{2}{|c|}{$\mathrm{Fas}^{+} \mathrm{CD}^{+} \% r=0.4, p<0.05$} \\
\hline & CD3+/HLA-DR+/ul & \multicolumn{2}{|c|}{$\mathrm{Fas}^{+} \mathrm{CD} 4^{+} / \mu \mathrm{L} r=0.4, p<0.05$} & \multicolumn{2}{|c|}{$\mathrm{Fas}^{+} \mathrm{CD} 8^{+} / \mu \mathrm{L} r=0.6, p<0.05$} \\
\hline & Adiponectin/BMI & \multirow{2}{*}{\multicolumn{4}{|c|}{$\begin{array}{l}\mathrm{Fas}^{+} \mathrm{CD}^{+} / \mu \mathrm{L} r=0.4, p<0.05 \\
\text { sFas concentration } r=-0.3, p<0.05\end{array}$}} \\
\hline & & & & & \\
\hline \multirow[t]{2}{*}{ 2. OSA indices } & EES & \multicolumn{2}{|c|}{$\mathrm{Fas}^{+} \mathrm{CD} 4^{+} \% r=-0.4, p<0.05$} & \multicolumn{2}{|c|}{$\mathrm{Fas}^{+} \mathrm{CD} 8^{+} \% r=0.06, p>0.05$} \\
\hline & $\mathrm{SpO}_{2}$ & \multicolumn{2}{|c|}{$\mathrm{GMF} \mathrm{Fas}^{+} \mathrm{CD}^{+} r=-0.3, p<0.05$} & \\
\hline \multirow[t]{2}{*}{ 3. Metabolic disorders } & BMI & \multicolumn{2}{|c|}{$\mathrm{Fas}^{+} \mathrm{CD}^{+} \% r=0.3, p<0.05$} & \multicolumn{2}{|c|}{$\mathrm{Fas}^{+} \mathrm{CD}^{+} \% r=0.3, p<0.05$} \\
\hline & TG & \multicolumn{2}{|c|}{$\mathrm{Fas}^{+} \mathrm{CD} 4^{+} / \mu \mathrm{L} r=0.4, p<0.05$} & & \\
\hline \multirow{3}{*}{$\begin{array}{l}\text { 4. Comorbidities } \\
\text { 5. Smoking history }\end{array}$} & \multicolumn{5}{|c|}{ Non-significant elevation of Fas+CD4 and Fas+CD8 cells in hypertension and COPD } \\
\hline & Pack-years smoked & \multicolumn{2}{|c|}{$\mathrm{Fas}^{+} \mathrm{CD} 4^{+} \% r=-0.3, p<0.05$} & \multicolumn{2}{|c|}{$\mathrm{Fas}^{+} \mathrm{CD}^{+} \% r=-0.4, p<0.05$} \\
\hline & & \multicolumn{2}{|c|}{$\mathrm{GMF} \mathrm{Fas}^{+} \mathrm{CD} 4^{+} r=-0.5, p<0.05$} & $\mathrm{GMF} \mathrm{Fas}^{+} \mathrm{CD}^{+} r=$ & $0.3, p<0.05$ \\
\hline
\end{tabular}

$B M I$ body mass index

$C O P D$ chronic obstructive pulmonary disease

ESS Epworth Sleepiness Scale

$G M F$ geometric mean fluorescence intensity

PLT platelets

$P M N$ polymorphonuclear cells

sFas soluble Fas

$\mathrm{SpO}_{2}$ peripheral capillary oxygen saturation

$T G$ triglycerides

found previously, the influence of smoking was striking when smoking history exceeded 20 pack-years [our unpublished data]. Of note, in this current study subjects with short exposure to tobacco smoke were included.

We carefully analyzed the relationship of Fas-positive cell populations with clinical and laboratory parameters. Interestingly, we did not observe any relation of Fas receptor expression with OSAS indices apart from $\mathrm{SpO}_{2}$. As in our previous report, a much stronger influence of metabolic and cardiovascular complications on immune cells was observed in this study. This relationship has also been reported by many other authors [14].

The correlation of Fas-positive cells with other inflammatory markers was of interest. Previously, we observed an elevated proportion of NK cells and NKT-like cells in OSAS patients. NKT cells form a complex population which was found to be an important link in immune regulation $[15,16]$. In our study, these two populations show 
Fig. 2 Scatter plots of correlations between Fas-positive $T$ cells and other variables. a Count of CD4+Fas+ lymphocytes and polymorphonuclear cells (PMN) percentage. b Count of CD8+Fas+ lymphocytes and PMN percentage. $\mathbf{c}$ Proportion of $\mathrm{CD} 4+\mathrm{Fas}+$ cell and NK cell percentage. $\mathbf{d}$ Proportion of CD8+ Fas+ lymphocytes and NKT cell percentage. e Counts of CD4+ Fas+ cells and NK cells. $\mathbf{f}$ Geometric mean fluorescence (GMF) of Fas receptor staining on $\mathrm{CD} 4+$ cells and oxygen saturation $\left(\mathrm{SpO}_{2}\right)$. Dashed lines show 95\% confidence intervals a

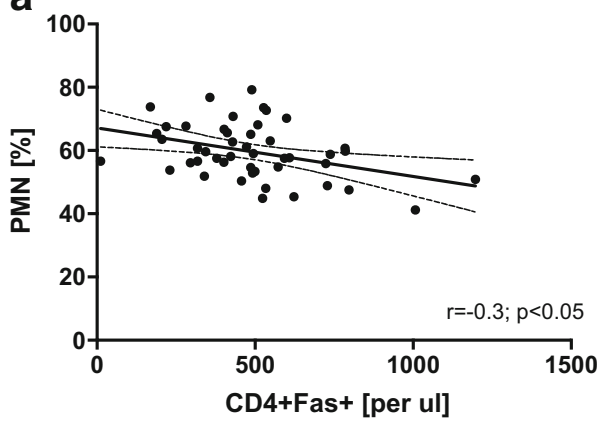

C

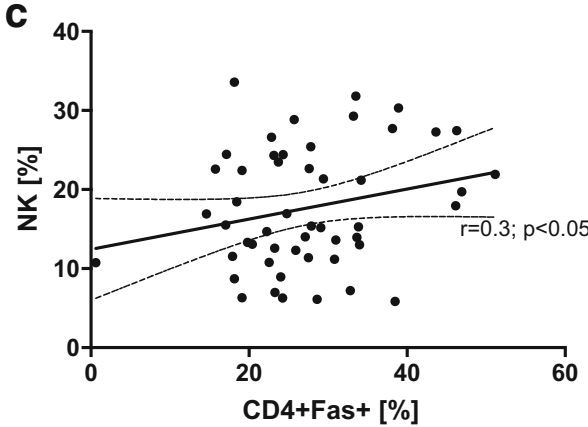

e

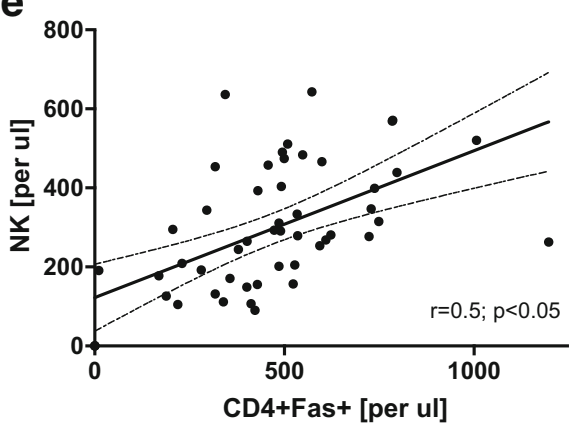

b
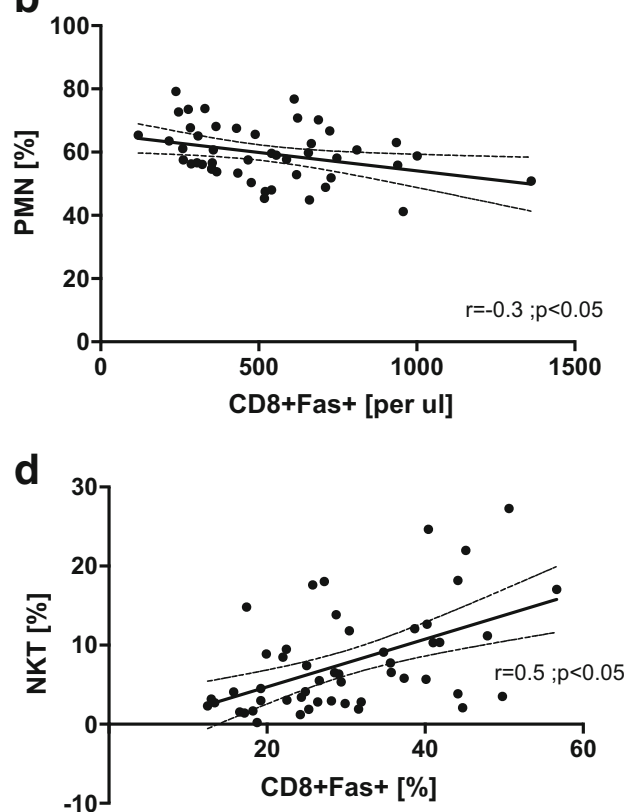

f

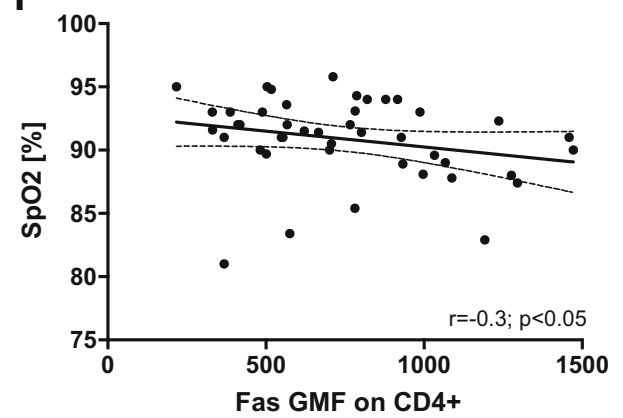

correlation with Fas-positive cells. Fas-positive cells also correlated with HLA-DR+ T cells, which are earlyactivated lymphocytes. This observation can indicate high turnover of $\mathrm{T}$ cells as these activated lymphocytes are prone to activation-induced cell death [17]. Previously, we confirmed the significance of adiponectin in the inflammatory process in OSAS as well as its complications. Adiponectin concentration to $\mathrm{BMI}$ ratio $(\mathrm{A} / \mathrm{BMI})$ correlated with the OSA complication score: the lower A/BMI index, the higher the risk of cardiovascular and metabolic complications of OSAS [3]. This study presents an important finding: Fas-positive cells and the concentration of soluble Fas were accompanied by a low value of A/BMI ratio. It shows the direction of immune response in OSAS, independent of metabolic disorders. We found a negative correlation of Fas-positive lymphocytes with neutrophils and platelets. The data concerning the value of neutrophil/lymphocyte and platelet/lymphocyte ratio in OSA in prediction of cardiovascular complications are conflicting and seem to be speculative [18-20]. Dyugovskaya et al. described prolonged survival of neutrophils in hypoxic conditions by inhibition of apoptosis [21]. Taken together, the associations of hypoxia and apoptotic pathways in OSAS need careful investigation.

The major weakness of our study was that we did not perform functional analysis of Fas-positive lymphocytes. In conclusion, we present for the first time the association of Faspositive lymphocytes with the systemic inflammation of OSAS.

Funding Grant WUM: 1WU/NM 2012

\section{Compliance with ethical standards}

Conflict of interest The authors declare that they have no conflict of interest.

Ethical approval All procedures performed in studies involving human participants were in accordance with the ethical standards of the institutional and/or national research committee and with the 1964 Helsinki declaration and its later amendments or comparable ethical standards. 
Open Access This article is distributed under the terms of the Creative Commons Attribution 4.0 International License (http:// creativecommons.org/licenses/by/4.0/), which permits unrestricted use, distribution, and reproduction in any medium, provided you give appropriate credit to the original author(s) and the source, provide a link to the Creative Commons license, and indicate if changes were made.

\section{References}

1. de Lima FF, Mazzotti DR, Tufik S, Bittencourt L (2016) The role inflammatory response genes in obstructive sleep apnea syndrome: a review. Sleep Breath 20:331-338

2. Wang J, Yu W, Gao M, Zhang F, Gu C, Yu Y, Wei Y (2015) Impact of obstructive sleep apnea syndrome on endothelial function, arterial stiffening, and serum inflammatory markers: an updated metaanalysis and metaregression of 18 studies. J Am Heart Assoc 4(11). https://doi.org/10.1161/JAHA.115.002454

3. Domagala-Kulawik J, Osinska I, Piechuta A, Bielicki P, Skirecki T (2015) T, B, and NKT Cells in Systemic Inflammation in Obstructive Sleep Apnoea. Mediat Inflamm 2015:161579

4. Guegan JP and Legembre P (2017) Nonapoptotic functions of Fas/ CD95 in the immune response. FEBS J 285(5):809-827. https:// doi.org/10.1111/febs. 14292

5. Le Gallo M, Poissonnier A, Blanco P, Legembre P (2017) CD95/Fas, Non-Apoptotic signaling pathways, and kinases. Front Immunol 8:1216

6. Yamada A, Arakaki R, Saito M, Kudo Y, Ishimaru N (2017) Dual role of Fas/FasL-Mediated signal in peripheral immune tolerance. Front Immunol 8:403

7. The Report of an American Academy of Sleep Medicine Task Force (1999) Sleep-related breathing disorders in adults: recommendations for syndrome definition and measurement techniques in clinical research. Sleep 22:667-689

8. Plywaczewski R, Brzecka A, Bielicki P, Czajkowska-Malinowska M, Cofta S, Jonczak L, Radlinski J, Tazbirek M, Wasilewska J (2013) [Sleep related breathing disorders in adults - recommendations of Polish Society of Lung Diseases. Pneumonol Alergol Pol $81: 221-258$

9. Dyugovskaya L, Lavie P, Hirsh M, Lavie L (2005) Activated CD8+ T-lymphocytes in obstructive sleep apnoea. Eur Respir J 25:820828
10. Tan HL, Gozal D, Wang Y, Bandla HP, Bhattacharjee R, Kulkarni R, Kheirandish-Gozal L (2013) Alterations in circulating T-cell lymphocyte populations in children with obstructive sleep apnea. Sleep 36:913-922

11. Kyaw T, Peter K, Li Y, Tipping P, Toh BH, Bobik A (2017) Cytotoxic lymphocytes and atherosclerosis: significance, mechanisms and therapeutic challenges. Br Aust J Pharm 174:3956-3972

12. Domagala-Kulawik J, Hoser G, Dabrowska M, Chazan R (2007) Increased proportion of Fas positive CD8+ cells in peripheral blood of patients with COPD. Respir Med 101:1338-1343

13. Hoser G, Wasilewska D, Domagala-Kulawik J (2004) Expression of Fas receptor on peripheral blood lymphocytes from patients with non-small cell lung cancer. Folia Histochem Cytobiol 42:249-252

14. Baffi CW, Wood L, Winnica D, Strollo PJ Jr, Gladwin MT, Que LG, Holguin F (2016) Metabolic syndrome and the lung. Chest 149: $1525-1534$

15. Gaoatswe G, Kent BD, Corrigan MA, Nolan G, Hogan AE, McNicholas WT, O'Shea D (2015) Invariant natural killer T cell deficiency and functional impairment in sleep apnea: links to cancer comorbidity. Sleep 38:1629-1634

16. Hogan AE, Corrigan MA, O'Reilly V, Gaoatswe G, O'Connell J, Doherty DG, Lynch L, O'Shea D (2011) Cigarette smoke alters the invariant natural killer $\mathrm{T}$ cell function and may inhibit anti-tumor responses. Clin Immunol 140:229-235

17. Krueger A, Fas SC, Baumann S, Krammer PH (2003) The role of CD95 in the regulation of peripheral T-cell apoptosis. Immunol Rev 193:58-69

18. Altintas N, Cetinoglu E, Yuceege M, Acet AN, Ursavas A, Firat H, Karadag M (2015) Neutrophil-to-lymphocyte ratio in obstructive sleep apnea; a multi center, retrospective study. Eur Rev Med Pharmacol Sci 19:3234-3240

19. Koseoglu HI, Altunkas F, Kanbay A, Doruk S, Etikan I, Demir O (2015) Platelet-lymphocyte ratio is an independent predictor for cardiovascular disease in obstructive sleep apnea syndrome. J Thromb Thrombolysis 39:179-185

20. Koseoglu S, Ozcan KM, Ikinciogullari A, Cetin MA, Yildirim E, Dere H (2015) Relationship between neutrophil to lymphocyte ratio, platelet to lymphocyte ratio and obstructive sleep apnea syndrome. Adv Clin Exp Med 24:623-627

21. Dyugovskaya L, Polyakov A, Lavie P, Lavie L (2008) Delayed neutrophil apoptosis in patients with sleep apnea. Am J Respir Crit Care Med 177:544-554 